\title{
A contribuição do princípio da precaução para a epistemologia do Jornalismo Ambiental
}

\section{The contribution of the precautionary principle to the epistemology of Environmental Journalism}

\section{La contribución del principio de precaución a la epistemología del Periodismo Ambiental}

Ilza Maria Tourinho Girardi,

ilza.girardi@ufrgs.br | http://orcid.org/o0oo-0001-8766-7139

Eloisa Beling Loose ${ }^{1, b}$

eloisa.beling@gmail.com | http://orcid.org/0000-0002-4755-3046

Débora Gallas Steigleder ${ }^{1, c}$

deborasteigleder@gmail.com | http://orcid.org/0000-0001-6030-5728

Roberto Villar Belmonte ${ }^{1, c}$

rvillar21@gmail.com | http://orcid.org/0000-0003-1561-2117

Carine Massierer ${ }^{1, c}$

cmassierer@yahoo.com.br | https://orcid.org/o0oo-0001-9231-3845

1 Universidade Federal do Rio Grande do Sul, Grupo de Pesquisa em Jornalismo Ambiental. Porto Alegre, RS, Brasil.
a Doutorado em Ciências da Comunicação pela Universidade de São Paulo.
b Doutorado em Meio Ambiente e Desenvolvimento pela Universidade Federal do Paraná.
c Mestrado em Comunicação e Informação pela Universidade Federal do Rio Grande do Sul.

\section{Resumo}

Neste artigo apresentamos os resultados preliminares de um projeto de pesquisa mais amplo sobre as epistemologias do jornalismo ambiental. O objetivo principal é verificar a origem e sustentação de aspectos epistemológicos do jornalismo dedicado ao meio ambiente. Apresentamos a proposta que impulsionou este estudo e, de forma específica, a análise realizada sobre um dos pressupostos pouco incorporados na cobertura de meio ambiente no Brasil até agora, que é a ideia da precaução. A análise é orientada por pesquisa bibliográfica com abordagem descritiva-qualitativa. Como resultado, constatamos que a literatura sobre jornalismo ambiental trata pouco da antecipação de riscos e danos, mesmo com o avanço da ciência em termos de previsões. Concluímos que a adoção do princípio da precaução se faz necessária em uma sociedade permeada por riscos fabricados pela própria humanidade.

Palavras-chave: Jornalismo; Jornalismo ambiental; Princípio da precaução; Epistemologia; Análise descritiva. 


\begin{abstract}
This article presents the preliminary results from alarger study effort about the epistemology of environmental journalism. The main objective was to verify the origin and the support of the epistemological aspects of journalism dedicated to the environment. We present the proposal that drove this study and, specifically, the analysis carried out on one of the barely incorporated assumptions in the environmental coverage in Brazil until now, which is the idea of precaution. The analysis is guided by bibliographic research, with a descriptive-qualitative approach. As a result, we identified that the literature on environmental journalism deals little with anticipating risks and damages, even with the advance of science in terms of predictions. In conclusion, the incorporation of the precautionary principle is necessary for a society in which predominate the risks produced by the humanity itself.
\end{abstract}

Keywords: Journalism; Environmental journalism; Precautionary principle; Epistemology; Descriptive analysis.

\title{
Resumen
}

En este artículo presentamos los resultados preliminares de un mayor esfuerzo de investigación sobre la epistemología del periodismo ambiental. El objetivo principal era verificar el origen y el apoyo de los aspectos epistemológicos del periodismo dedicado al medio ambiente. Presentamos la propuesta que impulsó este estudio y, de manera específica, el análisis realizado sobre uno de los supuestos poco incorporados en la cobertura ambiental en Brasil hasta ahora, que es la idea de precaución. El análisis se guía por la investigación bibliográfica, con un enfoque descriptivo-cualitativo. Como resultado, encontramos que la literatura sobre periodismo ambiental se ocupa poco de anticipar riesgos y daños, incluso con el avance de la ciencia en términos de predicciones. Llegamos a la conclusión de que la adopción del principio de precaución es necesaria en una sociedad impregnada de riesgos fabricados por la humanidad misma.

Palabras clave: Periodismo; Periodismo ambiental; Principio de precaución; Epistemología; Análisis descriptivo.

Este artigo pertence ao dossiê Comunicação e Meio Ambiente.

Contribuição dos autores:

Concepção e desenho do estudo: Ilza Maria Tourinho Girardi, Eloisa Beling Loose, Roberto Villar Belmonte

Aquisição, análise ou interpretação dos dados: Eloisa Beling Loose, Débora Gallas Steigleder.

Redação do manuscrito: Ilza Maria Tourinho Girardi, Eloisa Beling Loose, Débora Gallas Steigleder, Roberto Villar Belmonte, Carine Massierer.

Revisão crítica do conteúdo intelectual: Ilza Maria Tourinho Girardi, Eloisa Beling Loose, Débora Gallas Steigleder, Roberto Villar Belmonte, Carine Massierer.

Declaração de conflito de interesses: não há.

Fontes de financiamento: não houve.

Considerações éticas: não há.

Agradecimentos/Contribuições adicionais: não há.

Histórico do artigo: submetido: 20 mar. 2020 | aceito: 08 maio 2020 | publicado: 30 jun. 2020.

Apresentação anterior: não há.

Licença CC BY-NC atribuição não comercial. Com essa licença é permitido acessar, baixar (download), copiar, imprimir, compartilhar, reutilizar e distribuir os artigos, desde que para uso não comercial e com a citação da fonte, conferindo os devidos créditos de autoria e menção à Reciis. Nesses casos, nenhuma permissão é necessária por parte dos autores ou dos editores. 


\section{Introdução}

Ao tratar do Jornalismo Ambiental (JA), do que estamos falando? O que realmente diferencia a prática jornalística sob o ponto de vista do JA? Quais são suas bases e/ou pressupostos? O conceito já é relativamente conhecido no âmbito acadêmico, embora ainda haja confusões e generalizações (entende-se que tratar de um assunto associado ao meio ambiente é, automaticamente, JA, quando há entendimentos diferentes). Esta falta de diferenciação foi detectada pelo Grupo de Pesquisa Jornalismo Ambiental (CNPq/UFRGS), que atua há mais de dez anos na investigação das interfaces entre jornalismo e meio ambiente, e consta em estudo sobre o estado da arte da área ${ }^{1}$ e em pesquisa realizada com jornalistas que se consideravam ambientais ${ }^{2}$.

A partir de diferentes pesquisas, ao longo do tempo, identificamos que muitos dos pressupostos teóricos que sustentam a especificidade do JA acabam se tornando distantes da prática jornalística contemporânea, que tem cada vez menos profissionais especializados e menos tempo dedicado à produção jornalística. Diante disso, verificou-se que as bases de uma recente teoria que sustentasse essa distinção e reivindicasse um espaço diferenciado no campo jornalístico acabavam sendo mais prescritivas do que reais. Além disso, muitas características necessárias para a produção de um texto jornalístico que contemplasse múltiplas vozes e ampla contextualização são, na verdade, possíveis de serem concretizadas apenas em formatos muito específicos (e minoritários) dentro do escopo jornalístico, como a grande reportagem. Tais questionamentos nos levam a refletir como melhor aproximar os pressupostos teóricos de modo que eles sejam viáveis e coerentes com o jornalismo existente - e não aquele que idealmente deveria existir.

Diante disso, a pesquisa atual que desenvolvemos, chamada 'Estudo sobre aspectos epistemológicos do Jornalismo Ambiental', parte de investigações que se debruçam sobre as interfaces entre Jornalismo e Meio Ambiente para compreender as origens e pressupostos do Jornalismo Ambiental de forma crítica, esmiuçando suas características e debatendo sua viabilidade na prática. Tal estudo, iniciado em 2019, é norteado por uma pesquisa bibliográfica e de uma verificação descritiva-qualitativa guiada por um protocolo criado a partir dos objetivos da investigação. Dessa forma, identificamos o que orienta cada pressuposto, assim como sua origem e quem são os autores que o mobilizam. O objetivo é rastrear as especificidades desse jornalismo e escrutinar seus usos dentro do campo.

Em nossas pesquisas anteriores, engajamo-nos no esforço de construir bases neste sentido (apresentadas no tópico seguinte), as quais nem sempre são adotadas na prática da produção jornalística. Agora, nosso olhar é para observar o que constitui o embasamento epistemológico do JA.

Neste artigo, especificamente, apresentamos os primeiros achados desse esforço, a análise realizada sobre a incorporação do princípio da precaução no JA, um dos pressupostos que orientam a prática qualificada na área de meio ambiente defendida por nosso grupo de pesquisa. Tal princípio, porém, foi trazido para o debate mais tardiamente em comparação a outros, como a pluralidade de fontes e a visão sistêmica dos fatos. Metodologicamente, optamos pela pesquisa bibliográfica ${ }^{3}$ com abordagem descritiva qualitativa (já que a escassez e superficialidade da discussão encontrada no corpus não permitiram a aplicação do protocolo formulado para a pesquisa). Após exposição da conceituação do JA e de suas bases, discutimos a precaução e apontamos como ela tem sido articulada à cobertura de questões ambientais. Por fim, fomentamos um debate calcado nos resultados dessa fase.

\section{Do que falamos quando tratamos de Jornalismo Ambiental}

No Brasil, o JA pode ser visto como uma das especializações do jornalismo pelo menos desde a realização da Conferência das Nações Unidas sobre Meio Ambiente e Desenvolvimento realizada em 1992 no Rio de Janeiro ${ }^{4}$. Eventos e cursos preparatórios realizados pelo país antes e depois do encontro diplomático 
internacional ajudaram a consolidar essa especialização fortemente influenciada pelo jornalismo científico e pelo movimento ambientalista. Na época da Conferência do Rio, quando a especialização em temas relacionados ao ambiente se consolidou no jornalismo brasileiro, dois termos eram usados no Brasil para a denominação do profissional que atuava nessa nova área: jornalista ambiental e ecojornalista. O primeiro, mais próximo do jornalismo científico, era influenciado pelo jornalismo estadunidense onde foi criada em 1990 a Sociedade de Jornalistas Ambientais (SEJ, na sigla em inglês). O segundo, alinhado com a luta do movimento ambientalista, ganhou destaque no país com a criação, também em 1990, do Núcleo de Ecojornalistas do Rio Grande do Sul, primeira entidade brasileira a congregar jornalistas interessados nos temas ambientais.

Com o passar do tempo, outras denominações apareceram (e desapareceram), como 'jornalismo sustentável', por exemplo. Não vamos nos deter aqui na discussão das terminologias, pois entendemos que têm como ponto em comum a preocupação com a destruição do planeta. Nossa atenção está voltada aos elementos que sustentam esse tipo de jornalismo - e não às peculiaridades relacionadas ao contexto histórico e às estratégias mercadológicas que explicam escolhas no modo de dizer e nas ênfases adotadas. Independentemente de como chamamos ou conhecemos, o jornalismo que cobre meio ambiente pode ser entendido como uma especialização, diferente do jornalismo segmentado, que leva em consideração mais o público e seus nichos (segmentos).

O jornalismo especializado pode ser entendido como aquele que aborda com complexidade determinado tema, tendo como atributos: foco, aprofundamento, linguagem diferenciada e profissionais especializados ${ }^{5}$. Uma cobertura qualificada, segundo Wilson Bueno, também faz parte da definição de jornalismo especializado: "A prática profissional e também a subárea de estudos e pesquisas em Jornalismo que contemplam o processo de produção jornalística voltado para a cobertura qualificada de temas específicos. Ele [o jornalismo especializado] se manifesta a partir de fontes reconhecidas como competentes e autorizadas em determinadas áreas de conhecimento, e pela apropriação de um discurso especializado, que incorpora termos e expressões comuns (e muitas vezes exclusivos) dessas áreas. Na maioria dos casos, o Jornalismo Especializado se localiza em espaços (páginas, cadernos, programas, portais etc.) determinados, seja como resultado do trabalho individual de profissionais (jornalistas ou não) capacitados para exercê-lo, seja como fruto do trabalho de um grupo de profissionais, reunidos em editorias específicas"6.

O noticiário ambiental costuma ter, segundo Ricardo Garcia, quatro elementos em comum: a noção de risco, boa parte dos casos associada a processos longos, a incerteza científica e a complexidade técnica7. Todas essas quatro características permitem considerar esse tipo de cobertura como jornalismo especializado, e um dos termos utilizados para designar essa prática é jornalismo ambiental. Essa foi uma das primeiras definições de JA, proposta por Fernández-Reyes: “[...] preferimos proponer que se trata del ejercicio o periodismo especializado que atiende la información generada por la interacción del hombre o de los seres vivos con su entorno, o del entorno en sín.

Dentre as primeiras obras que ajudaram a divulgar a expressão 'Jornalismo Ambiental' no Brasil está o livro ‘Dez Dicas Práticas para Reportagens sobre o Meio Ambiente’, distribuído no país pelo Fundo Mundial para a Natureza (WWF) em 1994, e republicado em 1998 pelo Núcleo de Ecojornalistas do Rio Grande do Sul. De acordo com a publicação: “O jornalismo ambiental é um fenômeno relativamente recente. Trinta anos atrás, poucos repórteres escreviam com profundidade sobre esse tema”". Nesse manual, há uma concepção de jornalismo que defende uma postura equilibrada do profissional de grandes veículos.

"Um jornalista que escreva para uma revista de meio ambiente talvez concorde com a necessidade de advogar abertamente em favor das causas ambientais. Mas, na opinião de muitos profissionais, os repórteres que trabalham para grandes veículos desempenharão melhor seu papel e prestarão um melhor serviço aos leitores e telespectadores se não abraçarem nenhuma causa. Ninguém é a favor da poluição, mas há diferenças de opinião quanto ao que fazer a esse respeito, e quanto ao custo-benefício dos programas de despoluição. São assuntos sobre os quais é legítimo 
discordar. O mundo está cheio de opiniões conflitantes. [...] Os jornalistas não devem impor seus valores ao redigir uma reportagem"

A postura do profissional que cobre meio ambiente é um dos eixos que permeia a discussão do que seria JA. Da mesma forma que há autores como Nelson ${ }^{9}$ que pontuam um distanciamento do profissional em relação à pauta, há outros, como Trigueiro ${ }^{10}$, que postulam que é preciso marcar um lado em prol da vida, da sustentabilidade.

A concepção do que é jornalismo e natureza ou meio ambiente também influencia a prática profissional. Para Ricardo Arnt ${ }^{11}$, a principal dificuldade para começar a tratar dos temas ambientais na imprensa brasileira foi a presença entre os proprietários e editores dos principais veículos jornalísticos de uma ideologia pró-modernização de qualquer maneira. Por isso, segundo o autor, era preciso passar a abordar o meio ambiente de uma perspectiva menos exótica (biocêntrica) e mais econômica (antropocêntrica). "Para o ambientalismo crescer na política brasileira, vai ter que se apossar dessa coisa de recursos naturais e agendá-las numa perspectiva modernizante"11.

Já no início do século XXI, faltaria vitalidade ao jornalismo sobre meio ambiente devido à dificuldade de realização de grandes reportagens transversais, e tal disfunção precisaria ser corrigida, diagnosticou o jornalista e biólogo Eduardo Geraque ${ }^{12}$ depois de estudar reportagens sobre a poluição do ar publicadas entre 2000 e 2004 nos jornais ‘Reforma' e ‘La Jornada', da Cidade do México, e ‘O Estado de S. Paulo’ e ‘Folha de S.Paulo'. A norma encontrada pelo jornalista e pesquisador foi de textos sem espaço para a criatividade estilística ou noticiosa. $\mathrm{Na}$ avaliação de $\mathrm{Geraque}^{12}$, o comunicador deve ocupar o seu papel de mediar os conflitos sociais e não ficar em silêncio. Ter uma visão de mundo sistêmica, afirma o pesquisador, é a única forma de conseguir produzir reportagens impregnadas de transversalidade, caminho que possibilitaria oferecer ao leitor toda a complexidade contemporânea.

Já Pablo Gavirati ${ }^{13}$ propõe dois tipos de categorias para entendermos o JA: um jornalismo ambiental empírico (estudado dentro do discurso jornalístico) e um jornalismo ambiental conceitual (analisado desde o discurso dos movimentos sociais ambientalistas, do discurso político e do discurso acadêmico). "Entre lo que es y lo que puede ser existe una gran brecha, que consideramos fundamental en el abordaje de la crisis ambiental, do que su resolución implica una clara intervención en el futuro (mediato o imediato)"13. Assim, o JA é entendido de duas maneiras, como especialização profissional e como renovação do jornalismo, ambas relacionadas entre si. Ainda segundo o mesmo autor, é preciso distinguir uma notícia que trata de um tema ambiental de uma notícia que é comunicada de uma perspectiva ambiental.

Essa distinção entre notícias sobre temas ambientais e notícias comunicadas de uma perspectiva ambiental também vem sendo feita por Girardi, Schwaab, Loose e Massierer: "Não há uma definição consensual sobre jornalismo ambiental e o que afeta diretamente sua prática. Embora existam casos em que ele é tido como uma especialidade ou especialização jornalística, relacionada à cobertura de temas ambientais, entendemos que o jornalismo ambiental extrapola a ideia de ser uma cobertura centrada nos assuntos de meio ambiente. A concepção é outra, independente, baseada na pluralidade de vozes e na visão sistêmica, para além de uma cobertura factual ou programada"14.

O jornalismo ambiental, segundo essa perspectiva, precisa ser sistêmico e baseado na pluralidade de vozes. Ser sistêmico, na prática, significa que o repórter precisa perceber o fenômeno principal da pauta associado a outros fenômenos, e que só assim, tentando perceber o todo, será capaz de apresentar de maneira aprofundada os problemas com causas, consequências e possíveis soluções. Daí também a necessidade de uma diversidade de fontes. A cobertura factual, no entanto, não dá conta dessa pluralidade de vozes e de uma visão sistêmica. Por isso o Jornalismo Ambiental prescrito deve ser praticado por meio de reportagens em profundidade. Ele aparentemente não seria possível, portanto, no noticiário fragmentado do jornalismo diário - ou dependeria de uma frequência de publicações que ainda não é vista como suficiente. 
Por assumir compromisso com a sustentabilidade do planeta, o jornalista ambiental informa com a intenção de transformar, mobilizar e promover o debate: "O jornalismo ambiental, partindo de um tema específico (mas transversal), visa ser transformador, mobilizador e promotor de debate por meio de informações qualificadas e em prol de uma sustentabilidade plena. Para sua concretização é necessário buscar respaldo em olhares mais abrangentes, que possibilitem ver as conexões, superar a fragmentação reiterada. Fundem-se, desta forma, a natureza do jornalismo especializado com as demandas socioambientais que acabam por compor o horizonte de reflexão dos paradigmas emergentes"14.

A postura militante ${ }^{15}$ e a intenção de transformar ${ }^{14}$ estão presentes em outra obra escrita nos Estados Unidos e trazida para o Brasil por meio do livro do jornalista Michael Frome: "O jornalismo ambiental é diferente do jornalismo tradicional. Ele é jogado segundo regras baseadas em uma consciência diferente daquela predominante na sociedade. Ele é mais do que uma forma de fazer reportagens e escrever, mas uma forma de viver, de olhar para o mundo e para si próprio. Ele começa com um conceito de serviço social, dá voz à luta e às demandas e se expressa com honestidade, credibilidade e finalidade. Ele quase sempre envolve, de alguma forma, em algum lugar, riscos e sacrifícios"16.

De acordo com este autor, o Jornalismo Ambiental "[...] deve ser claro e compreensível, baseado em dados precisos e pesquisa extensa, sem deixar de refletir a imaginação do autor, seus sentimentos mais profundos e seu desejo de promover a causa de um mundo melhor"16.

Na mesma linha argumentam Girardi e colaboradores quando dizem que o JA reconhece os princípios do jornalismo científico, "[...] mas ultrapassa-o ao se propor sistêmico e complexo, fundamentado em uma ética e em uma cidadania ambiental, a ponto de sugerir que o ambiental, em sua transversalidade, 'contamine', ainda, as demais editorias"14.

Ressalta-se que a noção de jornalismo engajado também está presente entre os jornalistas chineses que praticam o jornalismo ambiental investigativo ${ }^{17}$.

Se o JA passa pelo caminho da especialização, ele necessariamente precisa abordar os temas de maneira aprofundada e sistêmica, ou seja, relacionando o fenômeno principal da reportagem com outros fenômenos naturais e sociais. Ele também deve ser engajado ${ }^{13-16}$. Por outro lado, o jornalismo sobre meio ambiente, muitas vezes, aparece de forma fragmentada, superficial e descontextualizada, características do formato notícia do gênero informativo. O jornalismo sobre meio ambiente não seria, portanto, apenas um jornalismo especializado, mas também um jornalismo que, por meio de sua abordagem ambiental, carrega sua mensagem transversalmente.

O JA que assumimos não é o mesmo que jornalismo que cobre pautas ambientais (como se fossem pautas políticas, esportivas ou policiais), mas aquele que na sua prática considera os valores do campo ambiental (ao menos parte deles) na construção das matérias, sendo elas aprofundadas ou não. Os pressupostos estudados pelo Grupo de Pesquisa Jornalismo Ambiental são resultado de um esforço coletivo de diferentes pesquisadores que, ao estudarem aspectos diversos do processo jornalístico atrelado à pauta ambiental, debateram o que seriam os fundamentos do JA. Os pressupostos epistemológicos dessa especificidade jornalística, detectados por inúmeros pesquisadores (como Wilson Bueno ${ }^{15}$, Ilza Girardi ${ }^{14}$, Eduardo Geraque $^{12}$, Pablo Gavirati ${ }^{13}$, Rogelio Fernández-Reyes ${ }^{8}$, Cláudia Moraes ${ }^{18}$, dentre outros) nos últimos dez anos, foram sintetizados por Loose e Girardi ${ }^{19}$ :

1. Ênfase na contextualização - a expectativa de superar a fragmentação e a descontinuidade; destaque para uma contextualização ampla, profunda e crítica (tecendo relações de causas e consequências) e a perspectiva sistêmica.

2. Pluralidade de vozes - as notícias deveriam representar a pluralidade de vozes que estão envolvidas com a questão, inclusive aqueles que não detêm legitimidade científica, empresarial ou política.

3. Assimilação do saber ambiental - a compreensão disto propõe novos valores e uma nova consciência para a prática jornalística a partir de um olhar ambiental. 
4. Cobertura próxima à realidade do leitor - trazer as questões ambientais para perto do cotidiano dos leitores e interconexão entre as escalas.

5. Comprometimento com a qualificação da informação - envolve engajamento e militância como atitudes críticas em defesa da sustentabilidade da vida.

6. Responsabilidade com a mudança de pensamento - o JA assume seu papel de contribuir para mudar o pensamento.

7. Incorporação do princípio da precaução - amplia o tempo de ação do jornalismo, orientando-o para o futuro na tentativa de alertar e evitar consequências negativas.

Dentre os sete pressupostos epistemológicos acima mapeados para o estudo maior, nos ocupamos neste texto apenas da incorporação do princípio da precaução, trazendo autores que discutem este tema e observando seu uso na literatura da área. Ressaltamos que esses são os primeiros achados de uma investigação coletiva, que abarca vários eixos de observação.

\section{Incorporação do princípio da precaução}

Quando o sociólogo alemão Ulrich Beck ${ }^{20}$ nomeia nossa sociedade contemporânea de "sociedade de riscos" ele coloca em xeque que os efeitos não calculados das ações humanas impactam (e tendem a impactar mais) a sociedade. Pela primeira vez, em contraste com épocas anteriores, a sociedade precisa encarar a si mesma, os perigos e riscos por ela mesma gerados. E é importante dizer que, para o autor, o meio ambiente permeia todas as nossas ações e faz parte do que entendemos por sociedade: "Problemas ambientais não são problemas do meio ambiente, mas problemas completamente - na origem e nos resultados - sociais, problemas do ser humano, de sua história, de suas condições de vida, de sua relação com o mundo e com a realidade, de sua constituição econômica, cultural e política. [...] No final do século XX, vale dizer: natureza é sociedade, sociedade (também) é "natureza" ${ }^{20}$.

Se antes a compartimentalização do conhecimento e a separação entre sociedade e natureza permitiam a especialização da ciência para promoção de soluções para a vida moderna, agora emergem uma série de questionamentos. A ciência passa também a ser causa de impactos (entre outras causas concorrentes), sendo vista "[...] como produto e produtora da realidade e de problemas que cabe a ela analisar e superar"

A ampliação da divulgação de incertezas por parte do campo científico e as constatações de que não temos controle sobre as consequências de muitos processos e produtos conduziram a um olhar mais cauteloso, que levou à discussão do princípio da precaução.

As primeiras discussões desse princípio começam nos anos 1970, em resposta à preocupação com a poluição industrial na Europa, e avançam em meados dos anos 1980, quando ocorre o debate para proteção da camada de ozônio, acarretando medidas de redução das emissões de substâncias como os clorofluorcarbonos ${ }^{21}$. Segundo Reichardt e Araújo dos Santos, esse princípio afirma que, na dúvida sobre o que irá acontecer, decide-se a favor do meio ambiente, mobilizando-se para lidar com a antecipação.

De acordo com Hammerschmidt ${ }^{22}$, na ordem internacional, houve reconhecimento dessa perspectiva como princípio autônomo em nível internacional na Segunda Conferência Internacional sobre proteção do Mar do Norte, em 1987, e na redação do documento derivado da Conferência das Nações Unidas sobre Meio Ambiente e Desenvolvimento, a Rio-92, expressa assim: "Com o fim de proteger o meio ambiente, o princípio da precaução deverá ser amplamente observado pelos Estados, de acordo com suas capacidades. Quando houver ameaça de danos graves ou irreversíveis, a ausência de certeza científica absoluta não será utilizada como razão para o adiamento de medidas economicamente viáveis para prevenir a degradação ambiental”23.

Desde então, o princípio da precaução vem sendo incorporado ao Direito Ambiental e demais discussões que tratem de temas carregados de incertezas. Diferentemente da prevenção, que busca atuar frente 
a problemas mensuráveis pela ciência, a precaução é chamada quando não há conhecimento dos danos ou não certeza de sua ocorrência e alcance de impacto. Outro aspecto que gera diferenciação é que "[...] enquanto a prevenção é um assunto de especialistas confiado em seus saberes, a precaução é um assunto que compete à sociedade em seu conjunto e deve ser gestionado em seu seio para orientar a tomada de decisões políticas sobre assuntos de relevância fundamental”21.

Considerando que o jornalismo lida muito mal com incertezas, já que estas podem ser ou vir a ser especulações, é de se imaginar que a precaução não seja algo muito considerado dentro do campo jornalístico. Jornalistas constroem seus relatos a partir de fatos concretos, reais. Os critérios de noticiabilidade vigentes orientam sobretudo a repercussão de acontecimentos já vividos, os quais possibilitam análises e mensurações posteriores. Em um contexto de mudanças globais de efeitos ainda não totalmente previstos, a não ampliação do entendimento sobre o que é considerado pauta pode prejudicar o papel social do jornalismo de informar aquilo que é de interesse público. No próximo tópico se observa o quanto essa ideia está distante da discussão jornalística hoje, apesar de todos sinais que estamos vivendo uma emergência ambiental sem precedentes.

\section{Análise do pressuposto que envolve precaução}

Nossa busca para análise do pressuposto que envolve a precaução centra-se em textos acadêmicos, publicados em formato de artigos em revistas científicas ou capítulos de livros, em língua portuguesa e espanhola - uma escolha do nosso Grupo para valorizar as investigações da América Latina, que costumam ser menos citadas justamente por não serem publicadas em inglês. A pesquisa foi feita nas seguintes bases de dados, selecionadas por serem de acesso livre e bastante conhecidas pelos pesquisadores de língua portuguesa e espanhola: Portal de Periódicos da Capesi, Google Acadêmico, Dialnet, SciELO e Latindex. Para encontrarmos artigos que debatessem a relação entre Jornalismo Ambiental e precaução, realizamos várias combinações nos dois idiomas mencionados, atrelando 'jornalismo ambiental' ou 'jornalismo + meio ambiente' a 'precaução' ou 'prevenção' ${ }^{\text {'ii }}$ ou "princípio da precaução". Neste primeiro movimento de pesquisa, focamos a construção do corpus somente em publicações científicas revisadas por pares.

Verificamos que as buscas em português e espanhol do pressuposto da precaução nos estudos de JA são restritas, sendo que a questão costuma ser citada, mas não desenvolvida, em termos teóricos/ epistemológicos. Foram encontrados apenas 24 textos até o momento da busca (dezembro de 2019) que apresentam uma das combinações citadas, sendo o mais antigo publicado em 2004.

Como os textos não desenvolveram a discussão da precaução no âmbito do JA, não conseguimos avançar na aplicação do protocolo criado para o estudo de todos os pressupostosiii, que prevê uma avaliação minuciosa da menção ao princípio, desde o mapeamento de autores e obras de referência para a utilização do conceito até a discussão sobre os limites de sua aplicação no campo do jornalismo. Entretanto, a inexistência de resultados alinhados ao objetivo da pesquisa guarda-chuva - ao menos na verificação desse pressuposto - permite-nos observar outros aspectos.

Pelo fato de os resultados encontrados sobre o pressuposto que versa sobre o princípio da precaução serem incipientes para corresponderem ao protocolo original da pesquisa, optamos por reorganizar os documentos recolhidos em um fichamento centrado no sentido atribuído às ocorrências do termo em cada

\footnotetext{
i Nesta base de dados, a busca de palavras-chave foi realizada através do campo 'buscar assunto' a fim de recuperarmos todos os resultados disponíveis que fossem compatíveis com nosso objetivo de pesquisa.

ii Mesmo entendendo que prevenção é diferente, incluímos o termo na busca por se aproximar semanticamente da ideia de antecipação dos problemas ambientais.

iii Recorda-se que o protocolo mencionado foi construído a partir da ideia de destrinchar todos pressupostos do JA de forma geral. Ele ainda será utilizado em outras análises, quando o debate teórico-epistemológico for mais aprofundado.
} 
um dos artigos. Desta forma, realizamos uma análise descritiva de viés qualitativo, a qual se aproxima da busca por explicações sobre fenômenos da realidade³ .

No âmbito das pesquisas descritivas com abordagem qualitativa ${ }^{24}$, assumimos como orientação metodológica a pesquisa bibliográfica ${ }^{25}$. De acordo com Gil $^{3}$, esse tipo de pesquisa permite desde a redefinição do problema de pesquisa até a interpretação dos resultados, abarcando leituras de diferentes tipos: exploratória, seletiva, analítica e interpretativa.

Conforme Antonio Carlos Gili3, após a elaboração do plano de trabalho, os passos seguintes são a identificação das fontes que serão consultadas e sua localização. Em seguida, o pesquisador deve fazer uma leitura exploratória para decidir se o texto consultado terá utilidade para a pesquisa. A leitura seletiva, que é a etapa seguinte, é mais profunda e permite a verificação da adequação do material aos objetivos do trabalho. Com os textos selecionados é possível efetuar a leitura analítica, que é de natureza crítica e possibilita ordenar as informações obtidas de forma que contribuam com a resolução do problema de pesquisa. Este autor destaca que é importante que o pesquisador adote a "atitude de objetividade, imparcialidade e respeito" para evitar o julgamento ${ }^{3}$. A última etapa do processo é a leitura interpretativa, que é mais complexa e "busca conferir significado mais amplo" 3 aos resultados obtidos na etapa anterior, procurando relações com outros conhecimentos. Com os apontamentos realizados, o pesquisador tem os elementos para a elaboração do relatório final.

Na busca em português, o resultado mais antigo é o trabalho de 2004, chamado "Os Transgênicos na Imprensa: o caso da liberação da soja Roundup Ready”, de autoria de Mariana Pereira Barboza ${ }^{26}$, no qual ela cita apenas uma vez, nas considerações finais, a ideia da precaução: "O projeto de lei que irá regularizar a biossegurança no país ainda está em tramitação no Congresso Federal e ainda não se pode afirmar quais características irão predominar, se a liberalização generalizada ou o princípio da precaução"².

Veja que nesse caso (como em outros a seguir) o princípio é posto como algo dado, que não exige explicações e nem está devidamente articulado aos pressupostos do JA, embora a autora parta dessa abordagem. Tal observação nos revela que, apesar da precaução ser cara ao JA, ela pode ser incorporada de forma mais pontual mesmo em pesquisas que se debrucem sobre o binômio jornalismo e meio ambiente.

Em espanhol, no mesmo ano, encontramos um texto de Rogelio Fernández-Reyes intitulado "Periodismo ambiental y periodismo sostenible" ${ }^{27}$, que faz menção ao termo prevenção em um momento: "Algunos de los rasgos en común del periodismo ambiental y el periodismo sostenible, pueden ser la interdisciplinariedad (los contenidos ambientales y los referidos a la sostenibilidad tienen claras connotaciones con otras áreas informativas y con otras disciplinas o ciencias); el que ambos tienen connotaciones de utilidad y servicio a los sujetos receptores (propone referencias éticas e invoca la modificación de conductas); se trabaja la actualidad como proceso (si en otro tipo de especialidad la actualidad constituye uno de los factores más relevantes los temas medioambientales y los referidos a la sostenibilidad se centran prioritariamente, en la 'prevención' de posibles riesgos o situaciones catastróficas); y ambas se mueven en realidades complejas frente a otros periodismos en el que predominan las evidencias (el largo plazo y la catástrofe son dos elementos comunes)"27 (grifo nosso).

Somente a partir de 2009 há mais resultados para a busca sobre o princípio da precaução. Este é citado no texto "A formação de representações sociais de transgênicos: a importância da exposição científica", de Juliana Mezzomo Allain e Clélia Maria Nascimento-Schulze ${ }^{28}$, - que, no entanto, traz o termo "jornalismo" somente nas referências e menciona os meios de comunicação de massa apenas enquanto fontes de informação sobre conhecimentos científicos. No mesmo ano, em "Tempo, ciência e consenso: os diferentes tempos que envolvem a pesquisa científica, a decisão política e a opinião pública”, José Aparecido de Oliveira e Isaac Epstein abordam a importância do princípio da precaução pelo olhar do jornalismo científico no contexto de "[...] formação e capacitação de uma opinião pública"29.

Ressaltamos que sete dos 24 trabalhos encontrados na busca são do âmbito do Grupo de Pesquisa em Jornalismo Ambiental. Destes, cinco contêm "riscos" - ou "riscos ambientais" ${ }^{\circ 0}$, ainda, "comunicação de riscos"31 
entre as palavras-chave, tendo sido publicados a partir de 2017. Nesse contexto, o princípio da precaução aparece vinculado à demanda por medidas prescritivas frente aos desafios ambientais da atualidade. Loose e Camana ${ }^{32}$ propõem em seu artigo, por exemplo, “[...] que o Jornalismo Ambiental pode contribuir para o enfrentamento e compreensão dos riscos inerentes à sociedade contemporânea. A reflexão que segue busca articular a construção social dos riscos com as contribuições que o jornalismo pode dar para disseminar outras ideias, compatíveis com o cuidado e o saber ambiental. O princípio da precaução é lembrado como ponto prioritário no fazer jornalístico responsável".

Nesse mesmo âmbito, o conceito é associado de forma recorrente à abordagem sugerida ao jornalismo sobre mudanças climáticas, referindo-se à adoção de práticas responsáveis frente às incertezas quanto à dimensão dos efeitos da ação humana sobre o clima global. "O princípio da precaução, que representa uma garantia contra riscos potenciais que, conforme o estado atual da ciência, ainda não podem ser identificados, é um aspecto relevante quando falamos de MCs, considerando as incertezas científicas e sua ameaça ao futuro. Entretanto, outros riscos ambientais deveriam se valer dele a fim de evitar prejuízos e danos às próximas gerações"30.

Um exercício metodológico que fornece pistas para uma definição do princípio da precaução pode ser observado no artigo "Dengue, Zika e Chikungunya: Análise da cobertura do risco de doenças associadas às mudanças climáticas sob a ótica do Jornalismo Ambiental”33, no qual o jornalismo é abordado no âmbito da comunicação de riscos. Uma das formações discursivas da análise empírica é chamada de "Precaução", a partir da evocação do Princípio da Precaução enquanto conduta voltada a alertar a sociedade sobre as consequências das alterações climáticas para a saúde humana e para o planeta. As autoras explicam que "[...] a FD Precaução é aquela que, em alguma medida, consegue formular à sociedade, o impasse civilizatório que vivemos, na medida em que indica que os riscos servem, de forma concreta, mesmo que ainda não comprovados, de alerta para que a sociedade tome novas posturas em relação à crise ambiental”33.

Aqui, vemos a associação deste princípio também aos estudos sobre saúde e qualidade de vida das comunidades humanas, relacionando-o ao impacto da biotecnologia sobre os organismos vivos - como no artigo de Guivant ${ }^{34}$, que dá continuidade à repercussão sobre a liberação de sementes transgênicas no país já observada no estudo de Barboza ${ }^{26}$ - e ao crescimento de epidemias globais e o consequente sentimento de insegurança que geram - como relatado por Gomes e Ferraz ${ }^{35}$, quando se referem ao discurso jornalístico sobre o contágio e a letalidade do vírus H1N1. Neste caso, ainda que abordada fora do escopo direto do Jornalismo Ambiental, a precaução é, mais uma vez, citada como orientação para a abordagem dos problemas estudados tanto pelo poder público, responsável pela regulamentação de práticas e proposição de políticas públicas, como pela instituição jornalística, que busca sintetizar as soluções possíveis e desejáveis para esses impasses a partir do contato com diversas fontes.

A única discordância sobre o posicionamento predominante no corpus de prudência em consideração às incertezas científicas foi localizada em Martins e Spink ${ }^{36}$. No artigo sobre medidas possíveis a partir das tecnologias da comunicação frente a desastres ambientais, os autores propõem a substituição de uma conduta de precaução absoluta que consideram "paralisante" - porque uma previsão que justifica alguma atitude de prevenção pode ser falha - por uma estratégia de "redução de danos", pois entendem o desastre como um contínuo, a partir de suas consequências catastróficas, em oposição à ideia de uma ocorrência isolada. "A redução de danos no processo comunicativo [...] dá-se por meio da redução do tempo entre obtenção da informação, tomada de decisão e ação. Quanto mais tempo dispendido com a obtenção da informação, menos tempo para agir em prol de salvar vidas"33.

Nenhum desses termos, no entanto, é propriamente conceituado para além de breves descrições sobre quais seriam as diferenças constitutivas entre ambos. 


\section{Considerações finais}

Após expormos a conceituação do JA e de suas bases, mencionamos o entendimento sobre precaução e analisamos como os trabalhos acadêmicos que constam nas bases de dados Portal de Periódicos da Capes, Google Acadêmico, Dialnet, SciELO e Latindex debatem a relação entre Jornalismo Ambiental e precaução.

A busca resultou em 24 artigos publicados entre 2004 e 2019, que mencionam o tema-chave deste artigo. Nenhum deles, todavia, se ocupa de uma discussão mais aproximada do que entendemos fundamental ao Jornalismo Ambiental: a incorporação do princípio da precaução na ação jornalística para que seu tempo de ação seja ampliado e trate não somente sobre presente, mas também sobre o futuro, na tentativa de alertar sobre as consequências de nosso atual modelo de vida e de organização social. Tal resultado pode ser decorrente da lógica jornalística, que é calcada nos fatos e não na previsão dos mesmos, não deixando espaço para a abordagem da precaução. Destaca-se que a maioria das pesquisas na área ainda se volta para o estudo dos produtos jornalísticos, olhando, portanto, para o presente e um passado recente.

Por meio dos artigos estudados, verificamos que o princípio da precaução é tão relevante para o direcionamento da conduta de jornalistas frente a temas derivados da crise ambiental de nosso tempo a ponto de ser entendido como dado e referenciado como um elemento partilhado pelo senso comum. Entendemos, portanto, a urgência de definir este conceito não somente para fins de adequação teórica nos trabalhos sobre jornalismo e meio ambiente, mas, sobretudo, para subsidiar uma necessidade empírica apontada nos trabalhos consultados, já que seus autores mencionam o princípio da precaução como argumento para a sugestão de aprofundamento das discussões suscitadas em suas pesquisas.

Em nossa análise, observamos o quanto a aplicação da ideia de precaução está ainda distante da discussão jornalística na academia e nas redações, apesar de todos os sinais de que estamos vivendo uma crise ambiental sem precedentes. Em termos de bibliografia, constatamos que as publicações que citam a expressão emergem nos últimos 15 anos, mas de forma periférica nas pesquisas sobre jornalismo e meio ambiente.

Além disso, apesar de existirem estudos e reflexões de nosso Grupo de Pesquisa sobre o tema, notamos uma lacuna no tensionamento dessa ideia com a literatura do jornalismo, de forma ampla, e do JA, de forma mais específica. Diante disso, assumimos a incumbência de realizar tal detalhamento nos seus trabalhos futuros, visto que o conceito é relevante para trabalhos em diversos campos de conhecimento - mas, sobretudo, no contexto de emergência climática. Dessa forma, vislumbramos um direcionamento possível para os estudos focados nas epistemologias que constituem o Jornalismo Ambiental.

\section{Referências}

1. Girardi IMT, Loose EB, Camana A. Panorama da pesquisa em Jornalismo Ambiental no Brasil: o estado da arte das dissertações e teses entre 1987 e 2010. In Texto. 2015;34:362-84.

2. Girardi IMT, Loose EB, Silva, JA. O Jornalismo Ambiental na concepção de quem o faz: estudo com jornalistas da América Latina, Caribe, Portugal, Espanha e países africanos de língua portuguesa. Aturá Rev Pan-Amazônica Comun. 2018;2:48-66.

3. Gil AC. Métodos e técnicas de pesquisa social. São Paulo: Atlas; 2008.

4. Belmonte RV. Uma breve história do jornalismo ambiental brasileiro. Rev Bras Hist Mídia [Internet]. 2017 [citado em 2020 fev. 20];6(2):110-25. Disponível em: http://www.ojs.ufpi.br/index.php/rbhm/article/ view/6656.

5. Fernandes AL. Jornalismo: especialização e segmentação. Curitiba: Intersaberes; 2017.

6. Bueno WC. Jornalismo especializado: resgatando conceitos e práticas. In: Santos M, Bueno, WC, organizadores. Jornalismo especializado no Brasil: teoria, prática e ensino. São Bernardo do Campo: UMESP; 2015. p. 279-301. 
7. Garcia R. Sobre a terra: um guia para quem lê e escreve sobre ambiente. Lisboa: Público; 2006.

8. Fernández-Reyes R. En torno al debate sobre la definicion del periodismo ambiental. Ámbitos [Internet]. 2003 [citado em 2020 fev. 20];(9-10):143-51. Disponível em: https://bit.ly/2LLfOVN.

9. Nelson P. Dez dicas práticas para reportagens sobre o meio ambiente. Washington: International Center for Journalists; 1994.

10. Trigueiro A. As obrigações do jornalismo ambiental [Internet]. Egypto, L., entrevistador. Rio de Janeiro: Mundo sustentável; 2006 jan. 06. [citado em 2020 fev. 27] Disponível em: https://mundosustentavel. com.br/as-obrigacoes-do-jornalismo-ambiental.

11. Arnt R. Imprensa discrimina o meio ambiente. In: Relatório do laboratório ambiental para imprensa realizado no Vale do Ribeira/SP. Fundação SOS Mata Atlântica: São Paulo; 1994. p. 73-80.

12. Geraque EA. Reportagens atravessadas: um mergulho, via Teoria Geral dos Sistemas, na cobertura da poluição atmosférica feita por jornais brasileiros e mexicanos [tese]. São Paulo: Universidade de São Paulo; 2006.

13. Gavirati P. Mediatizar el ambiente, ambientalizar los médios: tensiones en torno al discurso periodístico sobre el cambio climático. In: Fernández-Reyes R, Mancinas-Chávez R. Actas de las Jornadas Internacionales Medios de Comunicación y Cambio Climático. Sevilla: Fénix editora; 2013. p. 217-32.

14. Girardi IMT, Schwaab R, Massierer C, Loose EB. Caminhos e descaminhos do jornalismo ambiental. Comun Soc. 2012;34(1):131-52.

15. Bueno WC. Comunicação, jornalismo e meio ambiente: teoria e pesquisa. São Paulo: Mojoara Editorial; 2007.

16. Frome M. Green Ink: uma introdução ao jornalismo ambiental. Curitiba: Editora UFPR; 2008.

17. Tong J. The epistemology of environmental journalists: the case of China. Journal Stud [Internet]. 2017 [cited 2020 Feb 19];18(6):771-86. Available from: https://doi.org/10.1080/1461670X.2015.1076707.

18. Moraes $\mathrm{CH}$. Entre o clima e a economia: enquadramentos discursivos sobre a Rio+20 nas revistas Veja, Isto É, Época e Carta Capital [tese]. Porto Alegre: Universidade Federal do Rio Grande do Sul; 2015.

19. Girardi IMT, Loose EB. O Jornalismo Ambiental sob a ótica dos riscos climáticos. Interin. 2017 juldez.;22(2):154-72.

20. Beck U. Sociedade de risco: rumo a uma outra modernidade. São Paulo: Editora 34; 2010.

21. Reichardt FV, Araújo dos Santos MR. (In)eficácia do princípio de precaução no Brasil. Est Av [Internet]. 2019 [citado em 2020 fev. 19];33(95):259-70. Disponível em: https://bit.ly/2LQle1K.

22. Hammerschmidt D. O risco na sociedade contemporânea e o princípio da precaução no direito ambiental. Seqüência Est Jur Pol [Internet]. 2002 [citado em 2020 fev. 18];23(45):97-122. Disponível em: https://periodicos.ufsc.br/index.php/sequencia/article/view/15317/13912.

23. Ramind J, Ribeiro A. Declaração do Rio de Janeiro. Est Av [Internet]. 1992 maio-ago. [citado em 2020 fev. 18];6(15):153-59. Disponível em: https://bit.ly/2A3ZVXF.

24. Godoy AS. Uma revisão histórica dos principais autores e obras que refletem esta metodologia de pesquisa em Ciências Sociais. Rev Adm Emp. 1995;35(2):57-63.

25. Stumpf IRC. Pesquisa bibliográfica. In: Duarte J, Barros A, organizadores. Métodos e técnicas de pesquisa em comunicação. São Paulo: Atlas; 2005. p. 51-61.

26. Barboza MP. Os transgênicos na imprensa: o caso da liberação da soja Roundup Ready. Em Questão. 2004 jul.-dez.;10(2):435-47.

27. Fernández-Reyes R. Periodismo ambiental y periodismo sostenible. Ámbitos. 2004;(12):311-17.

28. Allain JM, Nascimento-Schulze CM. A formação de representações sociais de transgênicos: a importância da exposição científica. Psicol Teor Pesq. 2009 out.-dez.;25(4):519-30.

29. Oliveira JA, Epstein I. Tempo, ciência e consenso: os diferentes tempos que envolvem a pesquisa científica, a decisão política e a opinião pública. Interface. 2009;13(29):423-33. 
30. Loose EB, Camana A, Belmonte RV. A (não) cobertura dos riscos ambientais: debate sobre silenciamentos do jornalismo. Rev Famecos. 2017 set-dez.;24(3). doi: http://dx.doi.org/10.15448/19803729.2017.3.26545.

31. Loose EB, Girardi IMT. Antes do desastre: notas a respeito do Jornalismo, da comunicação de riscos, da prevenção e do envolvimento cidadão. Mediac Sociales. 2018;17:209-22.

32. Loose EB, Camana A. Reflexões sobre o papel do Jornalismo Ambiental diante dos riscos da sociedade contemporânea. Observatorio. 2015;9(2):119-32.

33. Moraes $\mathrm{CH}$, Girardi IMT, Loose EB. Dengue, zika e chikungunya: análise da cobertura do risco de doenças associadas às mudanças climáticas sob a ótica do jornalismo ambiental. Anu Elect de Estud Comunic Soc "Disertaciones". 2017 jul.-dez.;10(2):120-32. doi: http://dx.doi.org/10.12804/revistas. urosario.edu.co/disertaciones/a.4790.

34. Guivant J. Transgênicos e percepção pública da ciência no Brasil. Amb Soc. 2006 jan-jun.; 9(1):81-103.

35. Gomes IMAM, Ferraz LMR. Ameaça e controle da gripe A(H1N1): uma análise discursiva de Veja, IstoÉ e Época. Saúde Soc. 2012 abr.-jun.;21(2):302-13.

36. Martins MHM, Spink MJP. O uso de tecnologias de comunicação de riscos de desastres como prática preventiva em saúde. Interface. 2015;19(54) 503-14. 